\title{
A Interdisciplinaridade no cenário atual na percepção do docente de Ensino Fundamental e do estudante universitário
}

Leidiane Martins Ribeiro ${ }^{1}$, Aparecida Divina Rodovalho², Augusto de Paula Lemes ${ }^{2}$, Nayara Lima de Alencar ${ }^{2}$, Paulo Alexandre de Castro $^{3}$, Leonardo Santos Andrade ${ }^{3}$, Geraldo Sadoyama ${ }^{3}$, Adriana S.P.Sadoyama ${ }^{3}$

\section{Resumo}

A interdisciplinaridade é uma discussão emergente no meio educacional: uma forma de pensar, no interior da Educação, a superação da abordagem disciplinar tradicionalmente é fragmentária. A junção das disciplinas frequentemente é apontada como incapaz de atender às demandas por um ensino contextualizado. Embora esse enfoque não seja recente, pois as discussões sobre o tema no Brasil ocorrem desde a década de 1970 e somente nas últimas décadas têm encontrado terreno fértil para se propagar, em virtude de estarem presentes nos parâmetros oficiais, que norteiam a prática educacional, e no discurso de professores, coordenadores e administradores do ensino. O objetivo desse trabalho é apresentar as perspectivas e frustrações no estudo de caso da relação da interdisciplinaridade na escola de Ensino Fundamental e dentro da Universidade, tendo em vista que o sistema de ensino brasileiro busca sempre reproduzir os parâmetros dos grandes centros educacionais europeu e americano, todavia a base de ensino nacional atualmente encontra-se desestruturada na educação pública básica, sem sucesso nos métodos já aplicados, sem tempo, incentivo e formação para implantação da interdisciplinaridade. Inicialmente, os alunos bolsistas, juntamente com os respectivos coordenadores de área e a professora supervisora, realizaram reuniões de formação sobre o tema Interdisciplinaridade. Esses encontros, denominados reuniões interdisciplinares, eram realizados quinzenalmente com o objetivo de obter mais informações sobre o assunto. A partir das reuniões em busca da ligação das experiências dos alunos com a professora 
que atua no ensino público buscamos entender se a interdisciplinaridade dentro do Ensino Fundamental e na formação atual dos licenciandos existe de fato, ou ainda é considerada uma realidade distante muito discutida e pouco aplicada. A conexão das disciplinas comprovada com bons resultados seria um desafio? Ou as instituições de ensino não estão preparadas para a união dos docentes em prol de um objetivo? Percebe-se que esta forma de ensino exige do professor e da própria instituição um movimento de adequação, onde o lecionar deve se tornar interdisciplinar e a instituição de ensino deve se organizar para promover ações em conjunto. Isso confere ao modelo interdisciplinar certas complicações que exigem dos profissionais um se especializar, o qual não recebe reconhecimento ou apoio necessário do próprio sistema, de forma a desmotivar esse processo de mudança. Podemos concluir que este processo é uma construção contínua, que compreende uma modificação do próprio pensar daqueles que se encarregam da educação, transformando com o tempo a instituição, os profissionais, as ferramentas pedagógicas e o próprio sistema de ensino.

\section{Apoio: PIBID/CAPES}

$$
\begin{aligned}
& \text { P } \\
& \mathbf{a} \\
& \mathbf{l} \\
& \mathbf{a} \\
& \mathbf{v} \\
& \mathbf{r} \\
& \mathbf{a} \\
& \mathbf{s} \\
& \mathbf{C} \\
& \mathbf{h} \\
& \mathbf{a} \\
& \mathbf{v} \\
& \mathbf{e} \\
& \mathbf{S} \\
& \\
& \mathrm{I} \\
& \mathrm{n} \\
& \mathrm{t} \\
& \mathrm{e} \\
& \mathrm{r} \\
& \mathrm{d} \\
& \mathrm{i} \\
& \mathrm{s}
\end{aligned}
$$

a

a

v

a

s

C

h

a

v

e

n 